\title{
Dynamics of a small population of endangered huemul deer (Hippocamelus bisulcus) in Chilean Patagonia
}

\author{
Paulo Corti,* Heiko U. Wittmer, and Marco Festa-Bianchet \\ Département de Biologie, Université de Sherbrooke, Sherbrooke, Québec J1K 2R1, Canada (PC, MF-B) \\ Instituto de Zoología, Universidad Austral de Chile, Casilla 567, Valdivia, Chile (PC) \\ Wildlife, Fish, and Conservation Biology, University of California, Davis, CA 95616, USA (HUW) \\ School of Biological Sciences, Victoria University of Wellington, Wellington, New Zealand (HUW)
}

* Correspondent: paulo.corti@gmail.com

\begin{abstract}
Conservation of huemul (Hippocamelus bisulcus), an endangered South American deer, is hindered by a lack of quantitative information on its population dynamics. We conducted a 3-year study in Chilean Patagonia to assess the dynamics of huemul by monitoring known individuals. We fitted 55 deer of all sex-age classes with either radiocollars, radio ear tags, or conventional ear tags, and identified 33 additional deer through natural marks. Kaplan-Meier estimates revealed that annual survival of adult females was high and stable $(0.94 \pm 0.07$ $S D)$, but survival of female fawns was low and variable $(0.13 \pm 0.18)$. Predation was the predominant cause of mortality for deer of all age classes. Fertility rates were lower $(0.72 \pm 0.20)$ than in other cervids of similar size. Simulations of the finite rate of increase $(\lambda)$ suggest that the population is currently stable. Sensitivity analysis showed that any decrease in adult female survival would have drastic effects on $\lambda$. Consequently, management should maintain high adult survival and improve recruitment. Continued monitoring of individuals is required to provide baseline data for comparison with other populations and to inform recovery strategies of small and fragmented populations. DOI: 10.1644/09-MAMM-A-047.1.
\end{abstract}

Key words: Chile, conservation, demography, huemul deer, matrix models, survival

(C) 2010 American Society of Mammalogists

Of those mammal species with adequate information to assess conservation status, $25 \%$ are threatened with extinction (Schipper et al. 2008). Recovery of these species requires an understanding of the ecological and evolutionary dynamics of small populations (Lande 1988). Recovery also relies on knowledge of species-specific demographic parameters, which can identify factors affecting the risk of extinction (Caughley 1994; Sinclair et al. 2006). For example, estimates of survival are essential to quantify the role of environmental factors such as habitat loss in the decline of endangered species (Wittmer et al. 2007a). No estimates of demographic parameters exist for many endangered species including huemul (Hippocamelus bisulcus), the most threatened deer in South America (International Union for Conservation of Nature [IUCN] 2009). Lack of species-specific information often prevents development of effective recovery strategies.

Huemul are midsize deer endemic to the Andean forests of southern Chile and Argentina. Once abundant from central Chile $\left(34^{\circ} \mathrm{S}\right)$ to the Strait of Magellan $\left(54^{\circ} \mathrm{S}\right.$-Cabrera and Yepes 1960), their distribution has been reduced by $>50 \%$ since the arrival of Europeans (Flueck and Smith-Flueck 2006; Vila et al. 2006). The total remaining huemul population in 2007 was estimated at fewer than 2,000 individuals (IUCN 2009). The decline in distribution and abundance has been attributed to a variety of factors including habitat loss through conversion of native forest to farmland (Flueck and Smith-Flueck 2006; Frid 2001; Povilitis 1998), overhunting and poaching (Frid 2001; Povilitis 1998), competition from domestic livestock and infection by the exotic diseases they carry (Povilitis 1998; Simonetti 1995), and introduction of exotic species (Flueck et al. 2003). In the absence of detailed demographic studies, however, causes of decline remain speculative.

The objectives of this study were to estimate basic demographic parameters for a huemul population in Chilean Patagonia, including population density and rates of growth, fertility and recruitment, and age- and sex-specific survival. We also sought to identify the causes and temporal distribution of mortalities. We parameterized an age-structured matrix model (Caswell 2001; de Kroon et al. 2000) to determine the relative sensitivity of estimates of the finite rate

W w w. m a m m a log y. or g 


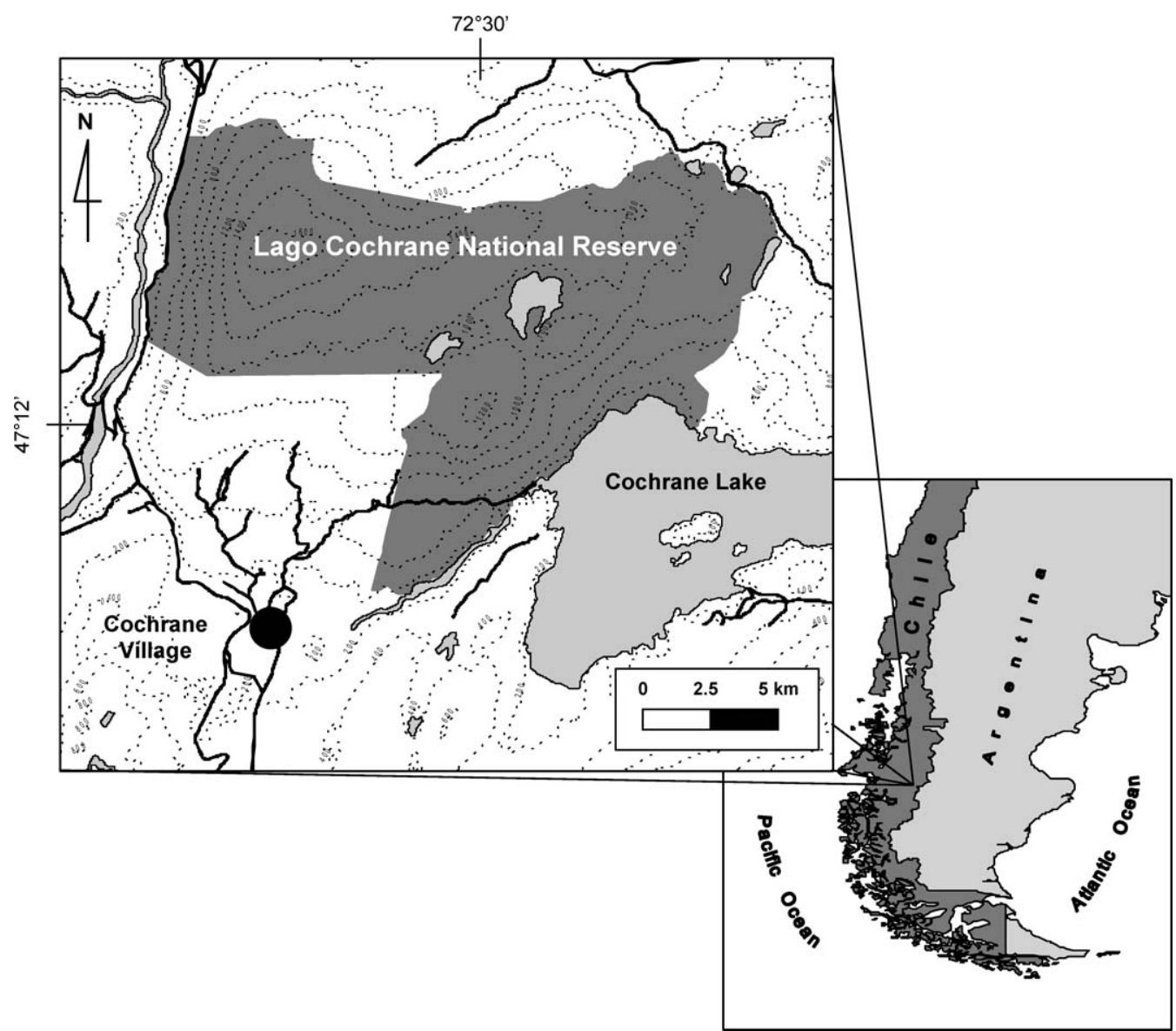

Fig. 1.- Study area at Lago Cochrane National Reserve, Aysén District, Chilean Patagonia. The reserve area is indicated in dark gray.

of increase $(\lambda)$ to changes in different vital rates. Such data are critical to develop effective recovery strategies for the species.

\section{Materials ANd Methods}

Study area.-The study area was in the Lago Cochrane National Reserve (LCNR; $69.25 \mathrm{~km}^{2} ; 47^{\circ} 12^{\prime} \mathrm{S}, 72^{\circ} 30^{\prime} \mathrm{W}$ ), Aysén District, Chilean Patagonia (Fig. 1). The LCNR was established in 1967 to protect southern beech forests dominated by lenga (Nothofagus pumilio) and one of the few remaining huemul populations in Chile. The vegetation of the reserve includes at least 204 species of vascular plants, of which $80 \%$ are native and $20 \%$ are exotic (Tomé and Teillier 2004). The canopy of the deciduous forest is dominated by lenga at high elevations and coihue $(N$. dombeyi) at lower elevations; the shrub layer is dominated by nirre $(N$. antarctica) and notro (Embothrium coccineum) trees, and the shrubs chaura (Pernettya mucronata), calafate (Berberis microphylla), and zarzaparrilla (Ribes spp.-P. Corti, pers. obs.). Evidence of old burned areas persists from humancaused fires between 1942 and 1945. Mean annual temperature in the LCNR is $7.6^{\circ} \mathrm{C}$ and annual precipitation is nearly $730 \mathrm{~mm}$, mostly falling between May and August (di Castri and Hajek 1976). Snow accumulates mostly during the southern winter from June to August.
Huemul capture and monitoring.-From 2005 to 2008 we captured 55 huemul. Deer were immobilized with a mixture of medetomidine (Zalopine; Orion Pharma, Espoo, Finland) and ketamine (Imalgene 1000; Merial SAS, Lyon, France) delivered with a dart gun. Newborn fawns were captured by hand. All captured huemul were marked with a colored and numbered ear tag (Allflex Inc., Palmerston North, New Zealand). Ages were estimated at capture from incisor eruption (Dimmick and Pelton 1994) and we used this information to group individuals into 4 age classes: fawns ( $0-1$ year), yearlings, 2 -year-olds, and adults (older than 3 years). We did not extract a tooth for aging these endangered animals because of the invasiveness of the procedure (Festa-Bianchet et al. 2002); thus, more detailed information on age structure is unavailable. Our sample of marked individuals included 21 fawns (15 males and 6 females), 2 yearling males, three 2 -year-olds ( 2 males and 1 female), and 29 adults (15 males and 14 females).

Nineteen individuals older than 1 year (6 males and 13 females) were fitted with very-high-frequency (VHF) radiocollars with mortality-motion sensors (Sirtrack Ltd., Havelock North, New Zealand). Our sample also included 2 adult females with VHF collars from a previous project (Gill et al. 2008). Eighteen fawns (14 males and 4 females) were fitted with VHF radio ear tags (Sirtrack) that transmitted for $7 \mathrm{~h} /$ day and lasted 12-14 months. All trapping and handling procedures were authorized by the Chilean Agriculture and 
Livestock Service (Servicio Agrícola y Ganadero [SAG]), were approved by the Université de Sherbrooke Animal Care Committee, an affiliate of the Canadian Council for Animal Care, and met guidelines approved by the American Society of Mammalogists (Gannon et al. 2007).

In addition, 33 deer (18 fawns, 3 yearlings, 3 juvenile males, 2 juvenile females, 2 adult males, and 5 adult females) were identified by natural markings, through associations with tagged individuals, and from their location within the study area. Locations of known individuals (with and without telemetry devices) were recorded by direct observations every 20-30 days between March 2005 and June 2008 using a handheld global positioning system (eTrex Summit; Garmin Ltd., Kansas City, Missouri).

Delineation of huemul use area.-We pooled all locations to establish the boundaries of the area used by huemul between 2005 and 2008. Including all recorded locations, we estimated a multiannual population range using the $95 \%$ adaptive kernel (Worton 1989) within the Animal Movement extension (Hooge and Eichenlaub 2000) in ArcView GIS 3.3 (ESRI 2002). We then divided the number of deer older than 1 year by the multiannual population range to estimate yearly densities.

Huemul population size, sex ratio, and density.-By January 2006 we could individually identify all deer within the LCNR. Thus, we estimated the number of huemul through direct counts conducted each November just before the parturition season. All observed individuals were sexed and aged. The sex ratio each year was estimated for all animals older than 2 years. Population density included all deer older than 1 year.

Causes of mortality.-Mortality was detected in 3 ways: when the signal from a motion-sensitive telemetry collar indicated that a huemul was dead we investigated the site as soon as possible (13 deaths); because animals were located at least once a month, the probability of finding dead deer was high, especially for adults, where detection was often aided by scavenger birds (11 deaths); and animals that disappeared were assumed to have died $(n=17)$. For this last category the last time an individual was seen was considered its date of death. Cause of death was determined from evidence found at the site, or from direct observations (e.g., dog attacks). Predation was attributed to cougar (Puma concolor), culpeo fox (Lycalopex culpaeus), and domestic dog (Canis lupus familiaris) based on tracks, scats, hair, state of the carcass (cougars generally bury their prey), and from predator sightings. Some deaths were attributed to poaching or to accidents. In $41.5 \%$ of cases the cause of death was unknown. We grouped mortality causes by age and examined their seasonal distribution.

Survival.-We used the staggered entry Kaplan-Meier procedure (Pollock et al. 1989) to estimate sex- and agespecific survival rates of huemul in the LCNR. Survival estimates were based on all individually identifiable huemul, with and without telemetry devices. We based our survival estimates on monthly time intervals and, with the exception of fawns, began calculations of yearly survival rates in April 2005. For fawns we began calculations of survival rates in December
TABLE 1.-Parameters $( \pm S D)$ used in matrix models to determine dynamics of the huemul population at Lago Cochrane National Reserve. Model 1 uses field-based age- and sex-specific (for fawns and adults) survival probabilities for all age-classes; model 2 assumes a $10 \%$ reduction in survival of adult females; and model 3 assumes a $10 \%$ reduction in survival of adult females but also increased fawn survival based on the pooled survival rate of female and male fawns.

\begin{tabular}{lccc}
\hline \multicolumn{1}{c}{ Parameters } & Model 1 & Model 2 & Model 3 \\
\hline Fertility & $0.72( \pm 0.20)$ & $0.72( \pm 0.20)$ & $0.72( \pm 0.20)$ \\
Survival & & & \\
$\quad$ 0-1 year (fawns) & $0.13( \pm 0.18)$ & $0.13( \pm 0.18)$ & $0.34( \pm 0.18)$ \\
1-2 years (yearlings) & $0.88( \pm 0.13)$ & $0.88( \pm 0.13)$ & $0.88( \pm 0.13)$ \\
2-3 years (juveniles) & $0.91( \pm 0.16)$ & $0.91( \pm 0.16)$ & $0.91( \pm 0.16)$ \\
$\geq 3$ years (adults) & $0.94( \pm 0.07)$ & $0.85( \pm 0.07)$ & $0.85( \pm 0.07)$ \\
\hline
\end{tabular}

2005, directly after parturitions. Because we treated animals that disappeared as mortalities, our survival estimates should be considered "apparent" estimates of survival. The decision to treat these animals as dead is justifiable because animals that emigrate stop contributing to population dynamics.

Fertility.-We estimated fertility directly from observations of marked females with a fawn. Huemul females produce 1 fawn per year, usually in late November and December (Diaz and Smith-Flueck 2000). In this study 3 females were observed with their 1 st fawns at 3 years of age and 1 at 4 years of age. Thus we assumed the age of primiparity to be 3 years.

Matrix models.-Matrix models have been used extensively to evaluate the dynamics of age-structured populations (Caswell 2001). Assuming an annual birth-pulse reproduction, we used survival and fertility estimates for each of the 4 age classes to parameterize a population projection matrix $(A)$ predicting population parameters in November (prebreeding) just before the birthing season:

$$
A=\left[\begin{array}{ccc}
0 & 0 & F_{3+} * p_{0} \\
p_{1} & 0 & 0 \\
0 & p_{2} & p_{3+}
\end{array}\right],
$$

where $F_{3+}$ is adult female fertility, $p_{x}$ is the age-specific survival probability, and the matrix columns represent age classes. From the matrix we predicted $\lambda$ and stable age distribution $(w)$ for huemul in the LCNR.

To assess how changes in fertility or age-specific survival would influence population growth we performed sensitivity analyses following Caswell (2001). All matrix analyses were performed using Microsoft Excel and the Excel add-in Pop Tools (Hood 2005).

Model parameterization.-We used estimates of agespecific survival and fertility rates from our field data. To account for uncertainty in parameter values for small agespecific sample sizes we compared 3 possible scenarios (Table 1), where we varied estimates of age-specific survival and fertility to assess sensitivity of model predictions to uncertainty in parameter estimates (Morris and Doak 2002). 
Table 2.-Estimated huemul population size (deer $>1$ year old) in the Lago Cochrane National Reserve in November 2005, 2006, and 2007. Sex ratio was calculated for individuals older than 2 years and population density for huemul older than 1 year. Yearly fertility was the number of fawns born divided by the number of females older than 3 years.

\begin{tabular}{lccccc}
\hline & 2005 & 2006 & 2007 & $\bar{X}$ & $S D$ \\
\hline Adults ( $\geq 3$ years) & & & & & \\
$\quad$ Male & 9 & 12 & 10 & & \\
$\quad$ Female & 14 & 19 & 20 & & \\
Juveniles (2 years) & & & & & \\
$\quad$ Male & 1 & 1 & 4 & & \\
$\quad$ Female & 2 & 1 & 2 & & \\
Yearlings & & & & & \\
$\quad$ Male & 1 & 5 & 2 & & \\
Female & 1 & 2 & 1 & & \\
Fawns & & & & & \\
$\quad$ Male & 4 & 3 & 4 & & \\
Female & 1 & 2 & 0 & & \\
Total population $(>1$ year old) & 28 & 40 & 39 & & \\
Sex ratio (\% females) & 63 & 65 & 64 & & \\
Density (huemul/km ${ }^{2}$ ) & 1.41 & 2.01 & 1.96 & 1.79 & 0.33 \\
Fertility & 0.94 & 0.55 & 0.68 & 0.72 & 0.20 \\
$\quad$ Fawns & 15 & 11 & 15 & & \\
Females & 16 & 20 & 22 & & \\
\hline
\end{tabular}

${ }^{\text {a }}$ Fertility estimates include 2-year-old females because at the time of count they become 3-year-olds and could have a fawn.

To account for uncertainty in estimates of vital rates we sampled both fertility and adult survival from a specified probability distribution following the approach described by Wittmer et al. (2007b). Values for vital rates were selected using the Excel function NORMINV (probability, mean, standard_dev), where "probability" is a uniform random number from 0 to 1 (selected using $\operatorname{RAND}()$ ), and "mean", and "standard_dev", were the estimate and standard deviations of each vital rate. Each set of randomly selected vital rates for the population then was used to construct a timeinvariant matrix population model. We repeated the procedure 1,000 times, resampling from the probability distribution of each vital rate for each replicate. Statistical analyses to determine confidence intervals for estimated $\lambda$, age distribution values, and reproductive values were conducted using the percentile method from the 1,000 repeated measurements (Efron and Tibshirani 1993).

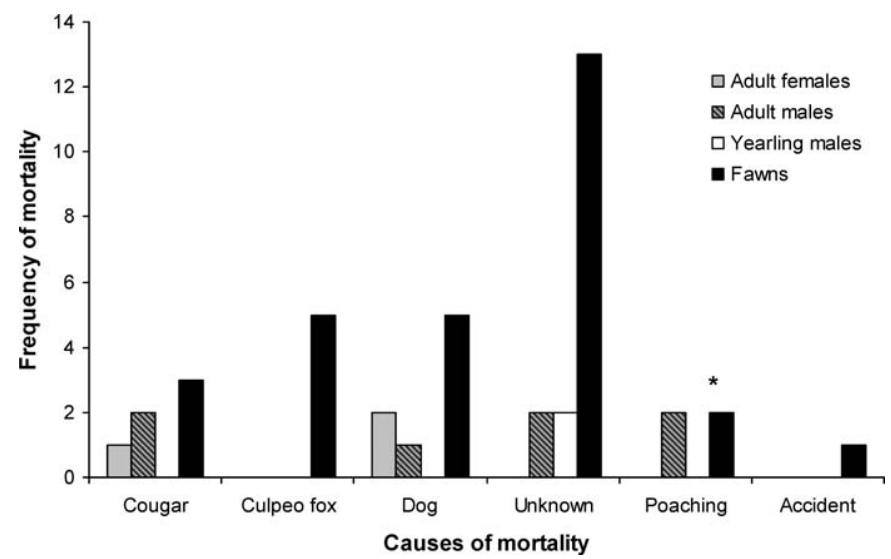

Fig. 2.-Causes of huemul mortality by sex-age class (male and female fawns were pooled) at Lago Cochrane National Reserve, Chilean Patagonia. An asterisk $(*)$ indicates 1 poached male from a previous project was included because the radiocollar was found during this study.

\section{Results}

Huemul demography.-The total area used by huemul deer was $19.9 \mathrm{~km}^{2}$, or $29 \%$ of the reserve. November counts for 2005, 2006, and 2007 indicated a population (excluding fawns) ranging from 28 to 40 individuals (Table 2). Sex ratios in all years were biased toward females. Mean $( \pm S D)$ density was $1.79 \pm 0.33 \mathrm{huemul} / \mathrm{km}^{2}$. Estimated fertility rates varied markedly among years.

Forty-one deaths were recorded between 2005 and 2008 (Fig. 2). Ten adults ( 7 males and 3 females) died, including a male marked during a previous project (not used for later analyses). Mortality in adult males was relatively evenly distributed among causes: 2 were poached, 2 were killed by cougars, 1 was killed by dogs, and 2 disappeared. One adult female was killed by a cougar and 2 were killed by dogs. For yearlings, causes of mortality were unknown; 2 yearling males disappeared. Cause of mortality was known for 16 of the 29 observed fawn mortalities; predation was the cause for 13 of these.

Fawn deaths occurred mostly in summer, during the first 3 months of life, and again in spring as fawns reached 1 year of age (Fig. 3). No fawns and very few adults died during the winter season. Causes of mortality did not show a clear seasonal pattern.

Survival probabilities of fawns were low during our study (Table 3), and survival of female fawns appeared particularly low. Survival probabilities of animals older than 1 year were

TABle 3.-Survival probabilities of huemul in the Lago Cochrane National Reserve from April 2005 and March 2008.

\begin{tabular}{|c|c|c|c|c|c|}
\hline & $\begin{array}{c}\text { Fawns } \\
\text { (females) }\end{array}$ & Yearlings & Juveniles & Females & Males \\
\hline $2005-2006$ & & 1.00 & 1.00 & 0.87 & 0.80 \\
\hline 2006-2007 & $0.34(0.25)$ & 0.75 & 0.73 & 0.95 & 0.85 \\
\hline 2007-2008 & $0.34(0)$ & 0.89 & 1.00 & 1.00 & 0.83 \\
\hline $\bar{X} \pm S D$ & $0.34 \pm 0(0.13 \pm 0.18)$ & $0.88 \pm 0.13$ & $0.91 \pm 0.16$ & $0.94 \pm 0.07$ & $0.83 \pm 0.03$ \\
\hline
\end{tabular}




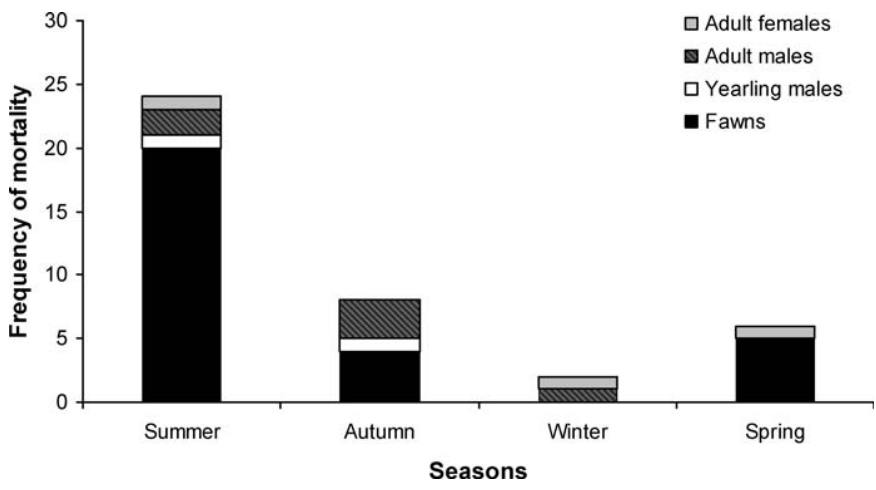

Fig. 3.- Seasonal mortality of huemul by age and sex class from March 2005 to June 2008 in Lago Cochrane National Reserve, Chilean Patagonia.

high and did not vary markedly among years. Survival probability was highest for adult females.

Matrix model and population trends.-A matrix based on observed parameters for fertility and survival predicts a stable population trend for huemul in the LCNR, although confidence intervals (CIs) are wide (Table 4, model 1). A $10 \%$ reduction in survival probabilities of adult females likely would result in a population decline (Table 4, model 2). Although $C I$ s for a scenario assuming reduced survival probabilities of adult females are wide, 729 of 1,000 runs resulted in $\lambda<1.0$ (Fig. 4, model 2). An approximately $60 \%$ increase in survival of female fawns would be required to reverse the potential effects of decreased survival of adult females (Table 4, model 3). CIs of stable age distributions overlap for all 3 models, suggesting that they were not significantly different. Observed age distributions in all 3 years fall within $C I$ s of the simulated age distributions for all 3 models. In all models $\lambda$ was most sensitive to changes in survival of adult females and fecundity (Fig. 5).

\section{DiscuSSION}

The huemul deer population at LCNR is extremely small, including only approximately 20 females of reproductive age.

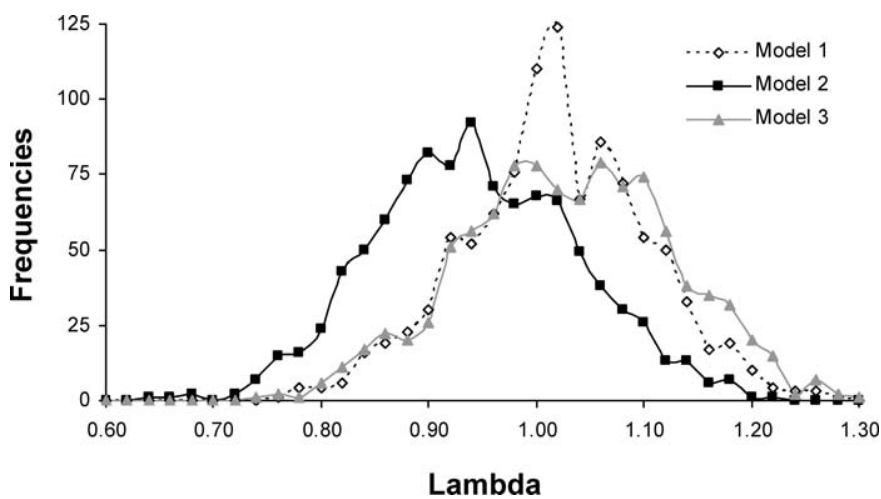

FIG. 4.-Frequency distribution of the finite rate of increase $(\lambda)$ for 3 different matrices calculated from 1,000 repeated random measurements of $\lambda$ around the estimated variance. Population parameters used for each model are in Table 1.
TABLE 4.-The finite rate of increase $(\lambda)$ and age distribution values (with 95\% CIs) for huemul estimated using a matrix model. Model input parameters are summarized in Table 1.

\begin{tabular}{llll}
\hline & \multicolumn{1}{c}{ Model 1 } & \multicolumn{1}{c}{ Model 2 } & \multicolumn{1}{c}{ Model 3 } \\
\hline$\lambda$ & $1.01(0.84-1.17)$ & $0.93(0.76-1.13)$ & $1.02(0.83-1.20)$ \\
Age distribution & & & \\
$1-2$ years (yearlings) & $0.08(0-0.21)$ & $0.08(0-0.21)$ & $0.15(0.01-0.27)$ \\
2-3 years (juveniles) & $0.07(0-0.16)$ & $0.07(0-0.18)$ & $0.13(0.01-0.21)$ \\
$>3$ years (adults) & $0.85(0.63-0.95)$ & $0.85(0.62-0.99)$ & $0.72(0.53-0.98)$ \\
\hline
\end{tabular}

Observed huemul densities were low and similar to those reported for other remnant populations (1 huemul $/ \mathrm{km}^{2}$ Smith-Flueck and Flueck 1997). Direct observations and the matrix models suggest that the population remained relatively stable over the 3 years of our study. The apparent increase in size of the population from 2005 to 2006 most likely was due to improved efficiency in finding and identifying deer and likely did not reflect an actual population increase. However, the very small size of the population, together with apparent isolation from other populations of huemul deer, poses a serious threat to the long-term viability of these animals in the LCNR.

We have presented the 1st estimates of vital rates for this species based on the observation of individually identifiable animals. Three factors suggest that these estimates should be considered preliminary. First, the short duration of our study and the small number of individuals in some age classes could have contributed substantially to sampling errors. Second, we might have underestimated fertility rates if we missed some fawns that died immediately after birth. Determining pregnancy rates from levels of progesterone in blood could increase the accuracy of our estimates of fertility, but it should be noted that these possible errors would not affect the estimation of $\lambda$, which was based on recruitment of weaned fawns. Third, our survival estimates could have been affected by pooling data from animals with and without telemetry collars. Despite these shortcomings, our study produced several results that are important to the conservation of this species.

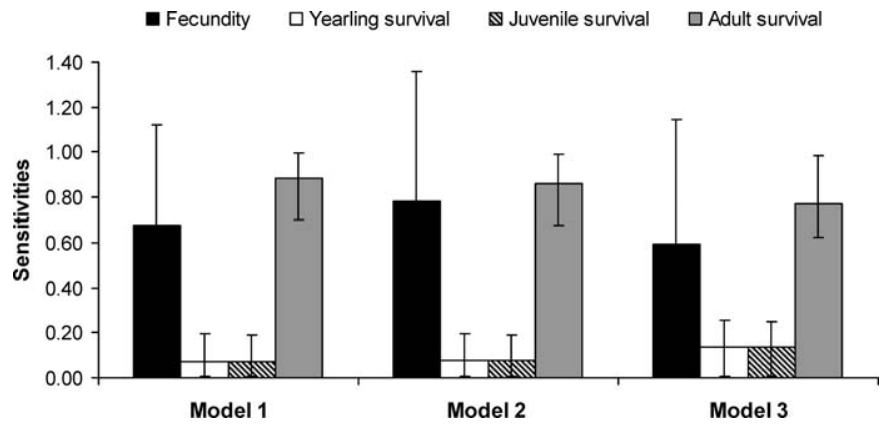

FIG. 5.-Sensitivities ( $\pm 95 \%$ CIs) for matrix parameters for huemul estimated from 3 matrix models (see Table 1 for definitions of matrix models and parameter values) at Lago Cochrane National Reserve, Chilean Patagonia, 2005-2008. 
Two contrasting aspects of individual survival currently determine the dynamics of the population. First, adult survival probabilities, particularly of females, appear high and constant. Second, survival of fawns (particularly females) appears low and variable. These findings are similar to data reported for other ungulates, where adult survival was typically stable and high, and survival among fawn and yearling animals was low and variable over time (Gaillard et al. 1998a, 2000). The apparent dependency of the population on high adult female survival implies that any reduction in female survival will result in a rapid decline of the population.

Our matrix analyses confirmed that changes in adult female survival will have the greatest potential effect on the rate of population growth, as is typical for ungulates (Gaillard et al. 2000). It often is inferred that management should focus on the parameters with the greatest relative influence (i.e., elasticity) on population growth (de Kroon et al. 2000). However, elasticity calculated from matrix projections will have no consequence for population dynamics if the vital rate in question does not vary over time. Instead, the vital rate with the highest combination of variability and elasticity should have the greatest effect on changes in population growth. For example, survival of adult female roe deer (Capreolus capreolus) was high and stable through time, suggesting that year-to-year changes in adult survival play a relatively minor role in changes in population growth (Gaillard et al. 1998b). Although survival of juveniles has low elasticity, because juvenile survival varies substantially from year to year, this parameter could have a major influence on variation in population size (Gaillard et al. 1998b). Thus it is essential that management actions for the LCNR population be directed at increasing recruitment while ensuring that adult female survival remains high.

Recruitment was low in general but especially for female fawns, which has important consequences for persistence of huemul deer in LCNR. During the last 2 years of our study only a small number of female fawns was born, and all died before reaching 1 year of age. It is likely that the male-biased fawn sex ratio was due to stochasticity, given the small sample size. Fawn mortality occurred primarily in summer, just after birth and during spring, coinciding with weaning. Although predation by foxes and dogs was a common cause of mortality, fawns were affected by all identified causes of mortality. Stochastic variability in fawn sex ratio would not be a problem if the population was sufficiently large to persist until the pattern reversed. This population of huemul deer is very small, however, as are most remaining populations of huemul deer in South America (Flueck and Smith-Flueck 2006; Povilitis 1998; Redford and Eisenberg 1992; Vila et al. 2006). Despite the high survival of adult females, a run of years with minimal recruitment could lead to a sudden decline as the population becomes older. Although we could not determine the age of onset of senescence, information from other ungulates strongly suggests that both increased mortality and reduced fertility can be expected among females 9 years old and older (Gaillard et al. 2000). Low recruitment of females is a significant conservation concern for small populations (Caughley 1994), and if this situation persists for huemul deer in our study area the population will likely go extinct.

Adult huemul deer in LCNR died mostly due to predation by cougars and dogs, and poaching. Most of our identified mortalities occurred in summer and autumn, a pattern that is atypical for many cervids where deaths often occur during winter and are related to malnutrition and starvation (Unsworth et al. 1999; White and Bartmann 1998; White et al. 1996). Although our results might suggest that forage availability in existing habitat was not limiting, this issue deserves more attention because the cause of many mortalities was unknown. The relationship between population growth for huemul deer and habitat quality is unknown. In addition, the apparent fertility of this population was low compared to that of other cervids of similar size (e.g., pregnancy rates of $>95 \%$ observed in white-tailed deer [Odocoileus virginianus] older than 2.5 years-DelGiudice et al. 2007), which could suggest food limitation or a senescent population (Gaillard et al. 2000).

Mortality from poaching and dog attacks presents opportunities for management. First, education efforts highlighting the potential benefits of tourism focused around endangered huemul deer may help reduce poaching (Freese 1997). Second, education is required to reduce dog attacks. Huemul do not have an effective antipredator strategy against cursorial predators such as dogs. The dog population in the nearby town of Cochrane is high and largely uncontrolled. If excursions of free-ranging dogs into the reserve remain at current levels or increase following the human population growth currently observed, dog control may be required in the near future.

Long-term persistence of huemul deer in our study area also could be compromised by increased levels of predation because local predators are increasingly subsidized by exotic alternative prey species. Apparent competition among herbivores as described by Holt (1977) recently has been identified as the ultimate cause of decline of several deer species including woodland caribou (Rangifer tarandus caribouWittmer et al. 2005; Wittmer et al. 2007a) and mule deer (Odocoileus hemionus-Robinson et al. 2002). We suggest that future research on huemul include an evaluation of the possible role of alternative prey (guanacos [Lama guanicoe], European hares [Lepus europaeus], and domestic livestock) on the abundance of cougars and culpeo foxes.

Increasing the huemul population in the LCNR and adjacent areas will depend on augmenting the survival of fawns and yearlings but also on the amount of habitat available. Adult males are territorial and huemul live in small groups, factors that also may limit population growth (Corti 2008). Thus, expansion and connectivity of habitats are fundamental to increase or at least stabilize this huemul population in the long term. Continued monitoring and tagging of huemul are necessary because longer-term monitoring and larger sample sizes are required to increase the precision of estimates and assess the impact of management actions. It also is essential to 
determine if the very low female recruitment that we documented was a stochastic event, and if it can be increased by appropriate management. Ultimately, such an understanding is required to predict confidently the fate of this small and fragmented population of huemul in Chile.

\section{RESUMEN}

La conservación del huemul (Hippocamelus bisulcus), un ciervo sudamericano en peligro de extinción, ha sido obstaculizada por la carencia de información cuantitativa sobre la dinámica de sus poblaciones. Esta investigación, realizada durante 3 años en la Patagonia chilena, determinó la dinámica del huemul a través del monitoreo de individuos marcados. Marcamos 55 huemules de todas las clases de edad y sexo con radio collares, radio aretes o aretes convencionales, e identificamos 33 individuos más a través de sus marcas naturales. Las estimaciones de supervivencia obtenidas con el método de Kaplan-Meier revelaron que la supervivencia anual de las hembras adultas era alta y estable (0.94 $\pm 0.07 S D)$, pero la de los cervatillos hembras fue baja y variable $(0.13 \pm$ 0.18). La depredación fue la causa predominante de mortalidad para todas las clases de edad en los huemules. Las tasas de fertilidad fueron más bajas $(0.72 \pm 0.20)$ que en otros cérvidos de similar tamaño. Las simulaciones de la tasa finita de incremento $(\lambda)$ sugieren que la población es estable por el momento. El análisis de sensitividad demostró que cualquier disminución de la supervivencia de las hembras adultas tendría efectos drásticos sobre $\lambda$. Por lo tanto, se recomienda que el manejo debe tratar de mantener alta la supervivencia de las hembras adultas y mejorar las tasas de reclutamiento. El monitoreo individual continuo es necesario para poder obtener los datos básicos para la comparación con otras poblaciones y para proponer estrategias para la recuperación de poblaciones pequeñas y fragmentadas.

\section{ACKNOWLEDGMents}

We thank the Denver Zoological Foundation (through R. Reading), Conservación Patagónica (through C. McDivitt), the National Geographic Society, Fundación Huilo-Huilo, Idea Wild, and Wildlife Conservation Society Field Veterinary Program for funding support. We are thankful to all people who helped in the capture of huemul and with the fieldwork: D. Velásquez, D. Jara, A. Sepúlveda, R. Millacura, H. Velásquez, C. Saucedo, J. Arnemo, and T. Ormeño. Special thanks go to D. Velásquez for his excellent assistance in the field. R. Sweitzer and 3 anonymous reviewers provided insightful comments on an earlier version of this manuscript. PC received support from a Natural Sciences and Engineering Research Council grant to M. Festa-Bianchet. Corporación Nacional Forestal, Aysén District Office granted access to the Lago Cochrane National Reserve. Huemul capture permits were issued by the Wildlife Subdepartment, Natural Renewable Resources Division of the Agricultural Service of Chile (SAG). P. Corti is deeply thankful to his family, Tania and Luciano, for their unconditional support through the process of this research and to his parents. This also is a contribution of Centro de Investigación de Ecosistemas de la Patagonia.

\section{Literature Cited}

Cabrera, A., and J. Yepes. 1960. Mamíferos sudamericanos. 2nd ed. Edian, Buenos Aires, Argentina.

CAswell, H. 2001. Matrix population models: construction, analysis, and interpretation. 2nd ed. Sinauer Associates, Inc., Publishers, Sunderland, Massachusetts.

Caughley, G. 1994. Directions in conservation biology. Journal of Animal Ecology 63:215-244.

CorTI, P. 2008. Organisation sociale, dynamique de population, et conservation du cerf huemul (Hippocamelus bisulcus) dans la Patagonie du Chili. Ph.D. dissertation, Université de Sherbrooke, Sherbrooke, Quebec, Canada.

de Kroon, H., J. van Groenendael, and J. Ehrlen. 2000. Elasticities: a review of methods and model limitations. Ecology 81:607-618.

Delgiudice, G. D., M. S. Lenarz, and M. C. Powell. 2007. Agespecific fertility and fecundity in northern free-ranging white-tailed deer: evidence for reproductive senescence? Journal of Mammalogy 88:427-435.

Diaz, N. I., AND J. A. M. Smith-Flueck. 2000. El huemul patagónico: un misterioso cérvido al borde de la extinción. LOLA (Literature of Latin America), Buenos Aires, Argentina.

di Castri, F., and E. R. Hajek. 1976. Bioclimatología de Chile. Universidad Católica de Chile Press, Santiago, Chile.

Dimmick, R. W., and M. R. Pelton. 1994. Criteria of sex and age. Pp. 169-214 in Research and management techniques for wildlife and habitats (T. A. Bookhout and W. Society, eds.). 5th ed. Wildlife Society, Bethesda, Maryland.

Efron, B., ANd R. Tibshirani. 1993. An introduction to the bootstrap. Chapman \& Hall, New York.

ESRI. 2002. ArcView GIS 3.3. Environmental Systems Research Institute Inc., Redlands, California.

Festa-Bianchet, M., P. Blanchard, J. M. Gaillard, and A. J. M. Hewison. 2002. Tooth extraction is not an acceptable technique to age live ungulates. Wildlife Society Bulletin 30:282-283.

Flueck, W. T., and J. M. Smith-Flueck. 2006. Predicaments of endangered huemul deer, Hippocamelus bisulcus, in Argentina: a review. European Journal of Wildlife Research 52:69-80.

Flueck, W. T., J. M. Smith-Flueck, and C. M. Naumann. 2003. The current distribution of red deer (Cervus elaphus) in southern Latin America. Zeitschrift für Jagdwissenschaft 49:112119.

Freese, C. H. 1997. Harvesting wild species: implications for biodiversity conservation. Johns Hopkins University Press, Baltimore, Maryland.

FRID, A. 2001. Habitat use by endangered huemul (Hippocamelus bisulcus): cattle, snow, and the problem of multiple causes. Biological Conservation 100:261-267.

Gaillard, J. M., M. Festa-Bianchet, and N. G. Yoccoz. 1998a. Population dynamics of large herbivores: variable recruitment with constant adult survival. Trends in Ecology \& Evolution 13:58-63.

Gaillard, J. M., M. Festa-Bianchet, N. G. Yoccoz, A. Loison, and C. ToIgo. 2000. Temporal variation in fitness components and population dynamics of large herbivores. Annual Review of Ecology and Systematics 31:367-393.

Gaillard, J. M., O. Liberg, R. Andersen, A. J. M. Hewison, and G. Cederlund. 1998b. Population dynamics of roe deer. Pp. 309-335 in The European roe deer: the biology of success (R. Andersen, P. Duncan, and J. D. C. Linnell, eds.). Scandinavian University Press, Oslo, Norway. 
Gannon, W. L., R. S. Sikes, and the Animal Care and Use Committee of the American Society of Mammalogists. 2007. Guidelines of the American Society of Mammalogists for the use of wild mammals in research. Journal of Mammalogy 88:809-823.

Gill, R., C. Saucedo, D. Aldridge, and G. Morgan. 2008. Ranging behaviour of huemul in relation to habitat and landscape. Journal of Zoology (London) 274:254-260.

HoLt, R. D. 1977. Predation, apparent competition, and structure of prey communities. Theoretical Population Biology 12:197-229.

HooD, G. M. 2005. Pop Tools, version 2.6.6. http://www.cse.cisro.au/ pooptools. Accessed 30 June 2005.

Hooge, P. N., And B. Eichenlaub. 2000. Animal Movement extension to ArcView. Alaska Science Center-Biological Science Office, United States Geological Survey, Anchorage.

International Union for Conservation of Nature (IUCN). 2009. International Union for Conservation of Nature Red list of threatened species. Version 2009.2. www.iucnredlist.org. Accessed 8 January 2010

LANDE, R. 1988. Genetics and demography in biological conservation. Science 241:1455-1460.

Morris, W. F., AND D. F. DOAK. 2002. Quantitative conservation biology: theory and practice of population viability analysis. Sinauer Associates, Inc., Publishers, Sunderland, Massachusetts.

Pollock, K. H., S. R. Winterstein, C. M. Bunck, And P. D. Curtis. 1989. Survival analysis in telemetry studies: the staggered entry design. Journal of Wildlife Management 53:7-15.

Povilitis, A. 1998. Characteristics and conservation of a fragmented population of huemul Hippocamelus bisulcus in central Chile. Biological Conservation 86:97-104.

Redford, K. H., AND J. F. Eisenberg. 1992. Mammals of the Neotropics. Vol. 2. The Southern Cone: Chile, Argentina, Uruguay, Paraguay. Vol. 2. University of Chicago Press, Chicago, Illinois.

Robinson, H. S., R. B. Wielgus, and J. C. Gwilliam. 2002. Cougar predation and population growth of sympatric mule deer and white-tailed deer. Canadian Journal of Zoology 80:556-568.

SCHIPPER, J., ET AL. 2008. The status of the world's land and marine mammals: diversity, threat, and knowledge. Science 322:225-230.

Simonetti, J. A. 1995. Wildlife conservation outside parks is a disease-mediated task. Conservation Biology 9:454-456.
Sinclair, A. R. E., J. M. Fryxell, and G. Caughley. 2006. Wildlife ecology, conservation, and management. 2nd ed. Blackwell Publishing, Malden, Massachusetts.

Smith-Flueck, J. A. M., And W. T. Flueck. 1997. Relevamiento de una población de huemul en la provincia de Río Negro, Argentina. Mastozoología Neotropical 4:25-33.

Tomé, A., AND S. TeILlier. 2004. Floristic richness of Tamango National Reserve. XI Región, Chile. XLVII Reunión Anual de la Sociedad de Biología de Chile. Biological Research 37, supplement A:R-14.

Unsworth, J. W., D. F. Pac, G. C. White, and R. M. Bartmann. 1999. Mule deer survival in Colorado, Idaho, and Montana. Journal of Wildlife Management 63:315-326.

Vila, A. R., R. López, H. Pastore, R. Faúndez, and A. Serret. 2006. Current distribution and conservation of the huemul (Hippocamelus bisulcus) in Argentina and Chile. Mastozoología Neotropical 13:263-269.

White, G. C., AND R. M. BARTMAnN. 1998. Effect of density reduction on overwinter survival of free-ranging mule deer fawns. Journal of Wildlife Management 62:214-225.

White, G. C., A. F. Reeve, F. G. Lindzey, and K. P. Burnham. 1996. Estimation of mule deer winter mortality from age ratios. Journal of Wildlife Management 60:37-44.

Wittmer, H. U., B. N. Mclellan, R. Serrouya, and C. D. Apps. 2007a. Changes in landscape composition influence the decline of a threatened woodland caribou population. Journal of Animal Ecology 76:568-579.

Wittmer, H. U., R. A. Powell, and C. M. King. 2007 b. Understanding contributions of cohort effects to growth rates of fluctuating populations. Journal of Animal Ecology 76:946-956.

Wittmer, H. U., A. R. E. Sinclair, and B. N. McLellan. 2005. The role of predation in the decline and extirpation of woodland caribou. Oecologia 144:257-267.

Worton, B. J. 1989. Kernel methods for estimating the utilization distribution in home-range studies. Ecology 70:164-168.

Submitted 2 February 2009. Accepted 14 December 2009.

Associate Editor was Harald Beck. 